\title{
So You Want To Get a Tenure-Track Job ....
}

\author{
Daniel W. Drezner, University of Colorado, Boulder
}

R elative to other kinds of employment, the process of getting a tenure-track job in political science is remarkably institutionalized. There is a specific timeline from August to March; APSA's Personnel Service Newsletter greatly reduces search costs; and the rules of conduct are well specified. The overall placement record of job applicants has remained between $69 \%$ and $74 \%$ over the past fifteen years (Rowdybush 1988; Brintall 1995), a figure higher than most of the humanities disciplines and comparable to the rest of the social sciences. Yet this is of little comfort to those who are actually entering the market. Despite the clear rules of the game, most graduate students enter the process with an utter lack of information concerning those rules and customs. Two years later, I recall the process as entering some giant void where there were no rules or guideposts. Little wonder that one scholar compared it to the garbage-can model of organizational behavior (Zahariadis 1994). Recent articles in $P S$ have provided some information about the formalities of the job market (Furlong and Furlong 1994; Anagnoson 1994), but were chary on practical advice. Better-informed job applicants will not be able to eliminate the uncertainty of the process, but they can convert it into risk, a more manageable commodity (Knight 1921).

There are three problems, however, that hinder the transmission of this information to graduate students. First, there is very little institutional memory within graduate

Daniel W. Drezner is an assistant professor of political science at the University of Colorado at Boulder. His teaching interests include international political economy, U.S. foreign policy, international organization, and international relations theory. He is the author of The Sanctions Paradox: Economic Statecraft and International Relations (Cambridge University Press, forthcoming). student associations. Those that get jobs leave soon afterward, before the next wave of candidates seriously thinks about the market. Advisors are supposed to provide this advice, but since their own experiences on the market are often decades old, they may not be of much use. Second, one could argue that the experiences accumulated on the market create what Michael Polanyi (1967) describes as "tacit knowledge." In other words, the knowledge culled from the experience cannot be transformed into accessible information. Third, since this sort of information has public-good qualities, rational choice scholars would predict the underprovision of advice (Olson 1965).

The following is offered as a guide for those first-time entrants into the political science job market. It provides some strategies for maximizing the chances of securing a tenuretrack position. It also offers advice on how to navigate through the decisions and, yes, the emotions generated in the process. It is based on my personal experiences as one who successfully navigated these waters two years ago and who has served on several hiring committees as a graduate student and as a professor. It also benefits from the recollections and experiences of several friends and colleagues. ${ }^{1}$

\section{The Six Commandments of the Academic Job Market}

1) This is a Capricious Process. The job market as a whole is institutionalized; the decision-making process within each hiring institution is somewhat more random. You might not get an interview just because your research does not fit the needs of any university. No one may be hiring in your field. The internal politics of other departments are as byzantine as those of your home institution, and you have no control over that (Zahariadis 1994; Anagnoson 1994). Expect randomness.

2) Do Not Expect to Get Much Research Done Between September and March. Whether or not you get interviews, it does not matter; the initial job search is an emotionally draining process. It will be difficult to focus on work. In planning out the rest of your dissertation, or other research projects, do not expect to get much accomplished during this period. On the other hand, once you do get a job from a department that expects you to have completed your dissertation, you will experience an impressive burst of productivity.

3) This is a Capricious Process. I am not kidding about this.

4) Publications Are Not Always a Prerequisite. Furlong and Furlong (1994) suspect that publications are more important than teaching credentials. That is true but incomplete. The important question is whether your dissertation committee believes you are doing interesting and sophisticated work: For graduate student applicants, hiring committees look at potential first and foremost. If your letters of recommendation show you have potential, attention will be paid to your application. Published papers and conference presentations matter, but they are not a necessary condition for employment. Candidates coming from a Top 20 institution will find this especially true. Applicants from lower-tier institutions are likely to find that publications become a more important factor.

Publications are also less relevant when applying to junior colleges, community colleges, and some liberal arts colleges. These institutions will be much more concerned with your ability as a teacher than as a researcher. Ironically, the bias at these places will be against a candidate with refereed publications coming from a Top 20 institution, be- 
cause there will be genuine skepticism that such a candidate would actually take the job if offered it.

5) Connections Will Not Get You a $J o b$. This process has two parts; getting an interview, and then getting an offer. No doubt, letters of recommendation and phone lobbying can help to get you an interview; that, however, is as far as this kind of influence can carry someone. At the interview stage, the quality of your work and your presentation determines whether you get the job.

6) This is a Capricious Process. In case you forgot.

\section{The Optimal Strategy for Graduate Students}

Furlong and Furlong (1994) provide a detailed description of the steps to follow while on the political science job market. This section describes the optimal strategy to adopt during this process. It is divided into the relevant time periods.

\section{Spring/Summer}

Select at Least Three Professors to Write You Letters of

\section{Recommendation}

Choose your letter writers with care, and make sure they know you and your work. The key people on your dissertation committee must write letters because otherwise, frankly, it looks odd. A hiring committee will wonder, "Why has that person's committee member failed to write a letter? Could it be because that advisor has qualms about this candidate?" Most places require only three letters, but you can and should send up to six, if possible. Be very careful here. Six strong letters are better than three strong letters. However, three strong letters are considerably better than three strong letters plus three letters that are either tepid or reflect a lack of knowledge about the candidate. Search committees will pounce on a lukewarm letter as an excuse to reject a candidate. Therefore, do not chase down big names just to get a letter of recommendation from them; only ask people that you feel know you well. Remember, it does not matter how much your advisor likes you; if the other letters are tepid, it devalues your entire application. Use the spring and summer to touch base with these people so that you feel comfortable enough to ask them about a letter of recommendation.

If possible, try to make sure that your dissertation committee, and by extension your group of letter writers, is not exactly the same as someone else who is going on the market. That invites a direct comparison between the two candidates, and inevitably one of the two candidates will suffer from the comparison. Hiring committees almost never interview two candidates from the same school. This does not mean that you are directly competing against all the other candidates, because research interests vary. Nevertheless, hiring committees will often compare letters about different candidates if they are written by the same person, because it is the one time a valid comparison is possible. Take the necessary steps to avoid this.

Liberal arts and community colleges have different hiring criteria than research universities. As noted previously, they will care more about teaching credentials. If you apply to these jobs, tell your recommenders this and get a different letter from them for these places, one that emphasizes your teaching. Otherwise, your letter writers will assume you want a research post and write an inappropriate letter.

\section{Make Sure You Have Enough Chap- ters/Articles to Send Out \\ As a rule of thumb, you need to include at least one theoretical chap- ter and one empirical chapter from the dissertation with each applica- tion. For three-article dissertations, two of them must be in presentable shape. If you fail to meet that stan- dard, no one will believe that you can finish your dissertation before the following summer. Departments will want to be assured and reas- sured that you will finish. Further- more, without enough chapters, rec-}

ommenders cannot adequately comment on your work.

Write Your Curriculum Vita (c.v.)

Your c.v. contains all your educational information, papers and presentations, research experience, teaching experience, and relevant work history. You must also state your birthday and country of citizenship. Be complete, although mentioning that you were captain of your high school debate team would most definitely be overkill.

Do not fall into the trap of obsessing about the c.v. So long as it has the vital information, it will be fine. Hiring committees do not care about the font. Have a professor look over it to make sure that the presentation is optimal, and have a friend look over it for typos; doing more is obsessive.

Send Out a Chapter/Article to a Journal for Review

Given the vagaries of the publishing process, a submission in the spring will probably not mean a publication by the fall. However, it does signal to hiring institutions that you are serious about your research program, and that you are determined to get your results into the public domain.

\section{August}

Ask Professors to Write Their Letters

Politely harass your recommenders at two-week intervals about their letters. Graduate students are understandably wary of being forceful with their advisors, but you need not feel guilty about this. Remember, your future is at stake. Everyone, including your advisors, understands this fact. You have every right to bug them.

\section{Start Looking through the APSA} Personnel Service Newsletter

The Newsletter is a monthly publication that lists job openings. Each ad contains the job description, the materials you need to send, and the deadline. Most departments receive a copy for graduate students to peruse. You can get your own sub- 
scription through APSA for $\$ 35$

(contact psn@apsanet.org).

Go to the APSA Annual Meeting, Even if You Are Not Presenting

By APSA, which is Labor Day weekend, you should have mentally prepared a snappy two-minute summary of what your research is all about. Important People will be asking you.

Furlong and Furlong (1994) observe that at APSA, there will be universities interviewing to fill jobs. Lots of liberal arts colleges take advantage of the Meeting to talk to people, and APSA has a system whereby you give them your $c . v$ and universities contact you if they want to interview you. However, as Anagnoson (1994) notes, these interviews count for little. For candidates with low self-esteem, the meat-market atmosphere can be gut-wrenching. However, these interviews do have one useful function; they are great practice for dealing with the requisite one-on-one faculty meetings at fly-out interviews. Think of them as a preview of coming attractions.

APSA is also an excellent time to ask yourself if you really want to stay in the academy. If you find conference presentations and incestuous gossip unbearable, perhaps academe is not the place for you.

\section{Make Sure You Know Your Field}

As a graduate student, you often hear that everything is interdisciplinary. Everything is, except the job market. Departments want to know whether you will teach international relations or comparative, American politics or political theory. The Furlongs erred in attempting to apply to any position where they could claim some competency. By the fortieth application, one could question whether the marginal benefit of applying was worth the marginal cost in time and money. Hiring committees, in whittling down an applicant pool from 150 to three or four, are looking for reasons to discard applications. Doubt about an applicant's area of specialty is an easy justification for moving that person to the rejected pile. If the majority of your letter writers are in a different field from the job listing, do not consider applying.

\section{Fall/Winter}

Send Out Application Packets to All the Relevant Schools

An application consists of a cover letter, curriculum vita, letters of recommendation, and samples of your work. Some schools will want a "teaching portfolio," which includes a statement on your teaching philosophy, course syllabi and reading lists, summaries of student evaluations, and sample assignments and tests. ${ }^{2}$ Others will want a graduate transcript or statements of research and teaching interests.

\section{Do Not Treat the Application Dead- lines Like Paper Deadlines}

Application deadlines are usually staggered between September 1 and January 1 . It will be tempting to send out application packets as each deadline approaches. This is both dangerous and a waste of effort. It is dangerous because you will find yourself panicking every two weeks, and your chances with the search committee are jeapordized. Hiring committees will often start to look at files before the official deadline, and they will pick out early favorites. If your application arrives early, the committee will have a chance to find out more about you if there is interest. If the application arrives late, however, it might be after committee members have developed a cognitive bias (Jervis 1968) towards the early favorites. Treating application deadlines like paper deadlines is a waste of effort because once you have crafted one job packet for a research university and one for a liberal arts college, you have them all courtesy of the copier machine. When the Newsletter shows new jobs available, just send the packet with a new cover letter. This will make life considerably easier, and might let you do some real work in the fall.

\section{After the Applications Are Out (November-January)}

Wait by the Phone, Hear Someone Else Has an Interview, and Panic

This part is not particularly fun, but remember, this is a capricious process. It is likely that you will get an interview. Different departments move at different speeds, so it may take some time. Just as the application deadlines are staggered, so are the notifications. Continue to apply to jobs posted in the Newsletter. The peak months are September through November, but there will be new listings after that. Just in case, start looking at post-doctoral fellowships if you want to leave your graduate school.

Just When Your Ego Is in Tatters, Receive a Phone Call Asking for a Job Interview and Arrange a Fly-Out Date

Most hiring institutions will want you there for the interview as soon as possible. Try not to get talked into flying out three days after they call you. Use any excuse you have, but try to get some breathing room. This allows you to give a practice talk to faculty at your home institution and incorporate their comments into the real job talk.

Both Furlong and Furlong (1994) and Anagnoson (1994) recommend asking for information about the hiring institution. Research the department a little to know who does work similar to yours. If you have time, read their latest publications. This flatters them (remember, all academics are considerable egotists). It also convinces them you will make a good colleague, which, beyond your field, is the principal question on everyone's mind.

The moment you tell anyone in your home department about a job interview, everyone else will find out in 48 hours. Do not try to hide the fact that you have an interview from people who do not have one because you think it will hurt their feelings. That sends a signal that you think they are too fragile to deal with it. Do not go skipping through the corridors either, but be straight-forward. 
Give a Practice Job Talk

This entails putting up flyers, lobbying faculty to show up (and not just your committee; at the real job talk, people from every subfield will be there), and whittling all 330 pages of your dissertation into a $30-$ to $35-$ minute presentation. The practice talk is useful even for those who have previously presented this material at a conference; there is a difference between a fifteen-minute presentation and a thirty-minute presentation. This will be the most nauseating and invaluable part of the whole experience. Once it is over, you will know exactly what to revise. And remember: in most cases, the real thing is much easier than the practice talk. Your advisors are usually aware of all of the weaknesses of your research; the faculty of the hiring department will not be as familiar with your work.

\section{The Job Interview}

Meet Lots of Faculty in 30-minute Intervals and Be Able to Make Small Talk with Each of Them ${ }^{3}$

The interview is a chance for the faculty of the hiring institution to assess you face-to-face, but it is also an opportunity for you to collect information about that institution. During the one-on-one meetings with faculty, ask the same questions of different people. Shockingly, you will get different answers, so this is valuable. They will ask you about your work; be sure to return the query. People in other fields are looking for a good colleague; they want to know if you care about anything other than your dissertation topic.

During these interviews, some questions are guaranteed, so prepare answers. You must be able to say what your next research project will be. You need to show people that you have a complete research program thought out. You will not be held to this later in life. You must be able to say what you can teach. Be flexible here, but do not say you can teach Chinese politics if you are applying to an American position. A good rule of thumb is, given a summer to prepare, what could you lecture about with confidence?

A recurring question will be whether your dissertation will be finished before the job starts. Every department's nightmare is hiring a graduate student and then having to wait two or three years before the Ph.D. is finished. When asked this question, stress your sincere desire and aim to finish the dissertation before the following fall if it is at all feasible.

This is the fun part. For the first time in your life, you will be treated as an equal by faculty. Savor it.

All of the illegal subjects will be addressed. Are you married? Where else are you interviewing? Do you plan to have children soon? Unfortunately, this problem seems to be more acute with female candidates. Most often, these questions are genuinely innocuous, and not intended to extract vital information. Therefore, finesse the questions if you can, but do not say, "That question is illegal." Technically, that might be accurate, but it indicates a prickliness that will turn off your colleagues. Hemming and hawing is fine, but citing the letter of the law wins no friends and will probably create enemies.

\section{Meet the Graduate Students}

The graduate students will say things that the faculty will not. They will be more blunt about how well the department is treating them. They will also be more candid in stating exactly what the hiring committee is looking for, as well as the internal politics and mood of the department. Take advantage of this.

Give a Job Talk of Less than Thirty Minutes and Then Answer All Questions in a Lucid Manner

Find out before your talk what the norm is; will people hold their questions until the end, or should you expect some queries during the talk? If questions are asked during your talk, do your utmost not to get sidetracked with answering persistent questioners. Tough questions are as much a test of your poise as the substance of the talk.

Everyone should know what your thesis is within the first five minutes, as well as why it is important. Passing what I fondly label the Krasner Test ("Why should I care about this? What's new here?") is crucial. Furthermore, remember that the overwhelming majority of people listening are not in your field. This does not mean you should pitch the talk to a third-grade level, but it does mean keeping the jargon to a minimum. Discuss ideas rather than referring to them in shorthand via a citation. Do not throw around author's names as if everyone will know them. A political theorist will not necessarily have heard of Robert Powell; an international relations theorist will not necessarily have heard of Susan Okin.

Remember that it is impossible to cram an entire dissertation topic into thirty-five minutes. Omit parts that disrupt the flow of the presentation. This works to your advantage during the question period, because, in all likelihood, listeners will ask about the omitted material, and you will have ready answers.

Appear interested in every question, no matter how inane. You do not have to agree with the criticism, but at least respect it.

At liberal arts schools, undergraduates may be at the job talks (find out beforehand). Pitch the talk accordingly. If the interview is at a liberal arts school, you will often be asked to guest-lecture a class. Graduate students often commit the cardinal sin of assuming that everyone else knows as much as their peer group of graduate students. This is 
not true, and acting on this assumption can be fatal in an interview, particularly when dealing with undergraduates.

\section{The Job Offer}

\section{Get It in Writing}

Those urban legends of candidates being offered jobs on the phone but finding them retracted a week later are true. This is not done on purpose, but rather reflects the state of disorganization or fractiousness at the hiring institution. Make sure you have a written contract in hand before assuming you have the job offer.

\section{Call Other Schools to See Where You Stand}

This is a rare moment of leverage. Schools will not rush their decisions just to accommodate you, as any student of bureaucratic politics knows. They can, however, hint at whether you should be expecting to hear from them in the future.

Lower-tier schools will tend to make offers earlier and set quicker deadlines. They do this because they are afraid desirable candidates will get better offers at more prestigious schools. Of course, they could be wrong. This is a judgment call. Remember, however, that APSA requires a two-week minimum between the offer and your response deadline (APSA 1991, 19).

\section{Negotiate}

There are several parts to a job offer: salary, benefits, teaching load, computer support, research support, moving expenses, and any initial time off. Anagnoson (1994) recommends that candidates should negotiate once the offer is in hand. There is some truth to this; by making their offer, the hiring department has invested a lot of time and effort and decided that they like you the best. That said, remember, that department heads, like heads of state, sometimes have constraints (i.e., deans and faculties) that prevent them from compromising (Putnam 1988). Asking never hurt anyone, but the only genuine leverage is another job offer.

\section{Not Getting the Job Offer}

\section{Avoid Withdrawing into a Shell}

Repressing bitterness is bad, but so is spewing it at anyone within shouting distance. Remember, this is a capricious process. If you can get funding, you should consider staying in your home department for another year. Going out on the job market for two consecutive years is becoming more common. Once your dissertation is finished or more polished, you may be looked at differently.

\section{Consider the Alternatives}

Deferring completion of your dissertation is one option, and this allows you to pursue other research projects. If you can get funding for this, all well and good. But this is frequently not an option. Other alternatives include post-doctoral fellowships and visiting positions. Post-doctoral fellowships usually last one year, occasionally with an option for two. Sometimes a fellowship will help, but not always. Obviously, the more prestigious the post- doc, the better. This strategy does point a shotgun at your head, however, because if you fail to get a job next year, you must find something else.

A word about visiting positions. Be wary of them. Universities hire instructors to exploit their teaching ability. It is difficult to teach, publish, and go out on the market at the same time. It is easy to get stuck in an endless cycle of one-year postings. Better to have two or three post-docs than two or three one-year teaching positions. That said, an increasing number of institutions are starting to establish explicit rules about the hiring and care of instructors and visiting professors. They are also lengthening the contracts offered to instructors. Find out about these rules before accepting any offer.

\section{Conclusion}

Although the political science job market is highly institutionalized, it is based on capricious decision making at the microlevel. This randomness makes it easy for first-time candidates to feel powerless entering the academic job market. The popular media's portrayal of the process as one of unmitigated gloom certainly does not help (Ellenberg 1997; Pfannestiel 1998). Nevertheless it is possible to improve one's chances by following the steps listed here. None of the advice provided here will eliminate the anxiety or the uncertainty involved in entering the academic job market. Hopefully, however, it will reduce it.

\section{Notes}

\footnotetext{
${ }^{1}$ I am grateful to Bari Anhaldt, Delia Boylan, Jeremy Buchman, Evan Feigenbaum, Page Fortna, Mark Lichbach, Eric Reinhardt, Kenneth Schultz, and Amy Zegart for their recollections and comments. The usual caveat applies.
}

\footnotetext{
${ }^{2}$ See Aliotta (1998) for more on teaching portfolios in political science.

${ }^{3}$ Go to the bathroom when you can. You are generally meeting people in 30-minute chunks, all of whom will give you coffee. Department
}

secretaries will forget this and assume your bladder is infinitely elastic. It sounds trivial, but you want all your energies focused on the person in front of you, not on crossing your legs. 


\section{References}

Aliotta, Jilda. 1998. "The Care, Feeding, and Uses of Teaching Portfolios." Presented at the annual meeting of the Midwestern Political Science Association, Chicago.

Anagnoson, J. Theodore. 1994. "Netting the Big One: Things Candidates (and Departments) Ought to Know... From the Hiring Department's Perspective." PS: Political Science and Politics 27(3): 558-62.

APSA Committee on Professional Ethics, Rights and Freedoms. 1991. "Principals of Professional Conduct: Ethics in the Recruitment and Hiring Process." A Guide to Professional Ethics in Political Science. Washington, DC: American Political Science Association.

Brintnall, Michael. 1995. "Placement Report: New Political Scientists on the Job Market in
1994." PS: Political Science and Politics 28(2): 260-63.

Ellenberg, Jordan. 1997. "The Great Ph.D. Scam.” The Boston Phoenix, March 6, 1.

Furlong, Deborah K., and Scott R. Furlong. 1994. "Netting the Big One: Things Candidates (and Departments) Ought to Know." PS: Political Science and Politics 27(1): 9197.

Knight, Frank. 1921. Risk, Uncertainty, and Profit. Boston: Houghton.

Jervis, Robert. 1968. "Hypotheses on Misperception." World Politics 20(3): 454-79

Olson, Mancur. 1965. The Logic of Collective Action. Cambridge, MA: Harvard University Press.
Pfannestiel, Todd. 1998. "It's Not Just a Job, It's an Indenture: Graduate Students and the Academic Job Market." Academe 84(1): 44. Polanyi, Michael. 1967. The Tacit Dimension. New York: Anchor Books.

Putnam, Robert. 1988. "Diplomacy and Domestic Politics: The Logic of Two-Level Games." International Organization 42(3): 427-60.

Rowdybush, J. Brinton. 1988. "Finding Jobs: Placement of Political Scientists in 1985-86." PS: Political Science and Politics 21(1): 8286.

Zahariadis, Nikolaos. 1994. "Garbage Cans and the Hiring Process." PS: Political Science and Politics 27(1): 98-99. 